DOI: 10.12731/2070-7568-2020-3-7-34

УДК 332.1:502.15(470.5)

\title{
АНАЛИЗ ПРОБЛЕМ «МУСОРНОЙ» РЕФОРМЫ И ТРАНСПОРТНЫХ ОРГАНИЗАЦИЙ-ПОДРЯДЧИКОВ В АСПЕКТЕ ЭКОЛОГО-ЭКОНОМИЧЕСКОЙ БЕЗОПАСНОСТИ
}

\author{
Белик И.С., Никулина Н.Л., \\ Аликберова T.T., Люцева А.Е.
}

Проблема загрязнения окружающей среды в современном мире проявляется как одна из ичентральных в системе «общество-природа». Частью этой проблемы и одновременно попьткой ее решения является проводимая в настоящее время «мусорная» реформа. В статье анализируются проблемы, связанные с такими аспектами «мусорной» реформы, как дуальная система сортировки мусора, транспортировка «разделенного мусора» специализированной техникой, обеспеченность организачий-подрядчиков необходимыми ресурсами, акцентируется внимание на вопросах доступности и стоимости авансируемого капитала на цчели модернизации транспортных средств.

Целью исследования является анализ соответствия проводимой «мусорной» реформы требованиям и критериям эколого-экономической безопасности.

В исследовании, с точки зрения эколого-экономических критериев, была поставлена задача оченки готовности предприятий, занятых в сфере транспортировки мусора, и определение потенциальных экономических угроз в период их реформирования.

Методы и методология: анализ научной и нормативно-правовой литературы, методы теоретических и эмпирических исследований, экономический и финансовый анализ, данные статистики.

Результат анализа. Предложен авторский подход к оченке проводимых мер на основе критериев эколого-экономической безопас- 
ности, выделенных с точки зрения ключевых элементов механизма управления эколого-экономической безопасностью.

Область применения результатов. Сфера транспортировки (организации-поставщики и подрядчики), несмотря на ограниченность финансовых средств, имеет ресурсньй потенциал, вариативность в выборе схем и источников финансирования, что существенно снижает экономические риски проведения реформы.

Ключевые слова: дуальная система сортировки; эколого-экономическая безопасность; сбор отходов; транспортирование отходов; сортировка мусора; региональный оператор; полигон ТКО; лизинг; стоимость источников финансирования.

\title{
THE ANALYSIS OF THE «WASTE» REFORM TRANSPORTATION CHALLENGES IN THE ASPECT OF ECOLOGICAL AND ECONOMIC SECURITY
}

\author{
Belik I.S., Nikulina N.L., \\ Alikberova T.T., Liutseva A.E.
}

The problem of environmental pollution in the modern world is one of the main problems in the "society-nature» system. Part of this problem, and at the same time an attempt to solve it, is the «waste» reform currently under way. The article analyzes the problems associated with such aspects of the «waste» reform as a dual system for sorting waste, transportation of «separated waste» with specialized equipment, provision of contractor organizations with the necessary resources, focuses on the availability and cost of advanced capital for the purpose of modernizing vehicles.

The purpose of the study was to analyze the compliance of the ongoing "waste» reform with the requirements and criteria of ecological and economic security.

In the study, from the point of view of ecological and economic criteria, the task was set to assess the readiness of enterprises involved in the transportation of waste, and to identify potential economic threats during the period of their reform. 
Methods and methodology: scientific and regulatory literature analysis, methods of theoretical and empirical research, economic and financial analysis, statistical data.

Results. The author's approach to assessing the measures being taken was proposed on the basis of the criteria of ecological and economic security, identified from the point of view of the key elements of the mechanism for managing ecological and economic security.

Practical implications. The transportation sector (supplier organizations and contractors), despite the limited financial resources, has some resource potential, variability in the choice of schemes and sources of financing, which significantly reduces the economic risks of the reform.

Keywords: dual sorting system; ecological and economic safety; waste collection; waste transportation; debris sorting; regional operator; MSW landfill; leasing; cost of funding sources.

\section{Введение}

Экологические проблемы общества, связанные с регулированием системы обращения с твердыми коммунальными отходами, в последние два года являются одними из основных для государства и регионов. Статистика свидетельствует о том, что ежедневно один житель России производит около 1,1 кг мусора, в год эта цифра составляет 400 кг. За 2019 год россиянами было сгенерировано около 70 миллионов тонн твердых коммунальных отходов (ТКО). Статистические данные свидетельствует о том, что проблема обращения с ТКО, возникшая как следствие практической деятельности, все более усугубляется, а ее решение лежит в плоскости применения новых подходов к управлению системой обращения с ТКО [12, 28, $31,33]$, и внесения изменений в законодательстве [14-16].

С 01.01.2019 года на территории РФ начал действовать закон [15], в соответствии с которым «сбор, транспортирование, обработка, утилизация, обезвреживание, захоронение твердых коммунальных отходов на территории субъекта РФ обеспечиваются одним или несколькими региональными операторами в соответствии с реги- 
ональной программой в области обращения с отходами и территориальной схемой обращения с отходами».

До выхода данного закона регионы в соответствии с другим Федеральным законом № 44 от 05.04.2013 «О контрактной системе в сфере закупок товаров, работ, услуг для обеспечения государственных и муниципальных нужд» [13] должны были провести конкурсный отбор региональных операторов, которые в свою очередь, для осуществления своей деятельности, должны были отобрать подрядчиков.

Для Свердловской области, которая рассматривается в качестве модельной территории в исследуемой проблеме, региональным оператором (Административно-производственный округ (АПО) №3 Восточная зона) в июне 2019 года в ходе проведения конкурсного отбора был выбран генеральный подрядчик в сфере обращения с твердыми коммунальными отходами (ТКО) - ООО «ТрансСервис» (подрядчик ЕМУП Спецавтобаза).

Новшеством для Свердловской области в сфере обращения с ТКО стал ввод иной схемы сортировки бытового мусора, сроки которой определены с июля 2020 года. Вводимая система называется дуальный способ сбора отходов, ее реализация означает, что у населения появляется новая обязанность по разделению мусора на органический и неорганический (не гниет с выделением «свалочного» газа). Согласно данному способу сбора отходов предлагается установить во дворах, как минимум 3 контейнера: для «мокрого» мусора, для «сухого» и отдельно - сетки для пластика [7]. В соответствие с новой градацией к «сухому» мусору (неорганическому) относятся стекло, пластик, макулатура, полиэтилен, изделия из резины; к «мокрому» - органические отходы (очистки овощей, фруктов; кости, шкура от разделки мяса, рыбы), средства гигиены и др.

Ввод данной схемы накопления ТКО, по мнению руководства региона, является первым шагом к полноценной их переработке и утилизации. В отличие от системы раздельного сбора мусора [5], при дуальной системе потенциальное вторсырье (неорганический мусор) собирается в один контейнер, затем досортировывается и очищается на мусоросортировочных комплексах, вручную специ- 
алистами или с помощью техники и далее разделяется на фракции для последующей переработки; отходы органического происхождения - уходят на утилизацию (сжигание, захоронение).

По мнению законодателей, предпринятые меры должны способствовать уменьшению количества несанкционированных свалок, снижению негативного воздействия на окружающую среду, в том числе от повторного загрязнения, а также повышению переработки таких, пригодных для вторичного использования отходов, как пластик, стекло, бумага. Кроме того, власти рассчитывают, что для стимулирования населения важно предусмотреть возможность снижения «мусорного» тарифа. В анализируемом варианте затраты, связанные с переходом на дуальную систему, ложатся на региональных операторов и бюджет.

Однако до настоящего времени остаются открытыми множество вопросов, связанных с хозяйственной готовностью и повышением уровня финансовых рисков предприятий (организаций), занимающихся сбором, транспортировкой и утилизацией отходов, к уже введенным и предлагаемым к вводу мерам. Основными из них являются следующие:

- нехватка контейнеров и баков для раздельного сбора мусора, ограниченность наличия специальной техники, которая должна вывозить контейнеры разных типов;

- наличие на территории Свердловской области крупных мусоросортировочных комплексов, куда будут свозиться отходы для разделения на перерабатываемые фракции и достаточность их производственных мощностей для увеличения пропускной способности;

- наличие у производителей контейнеров, предназначенных для раздельного сбора мусора, возможности по их маркировке, цветовому решению для каждого вида мусора;

- соответствие требованиям экологической безопасности территориальных схем обращения с отходами и др.

При их решении следует учитывать и такие практические задачи, вызванные требованиями экологической безопасности, как ис- 
ключение попадания в эти баки опасных отходов: батарейки, люминесцентные лампы, и т.д. для которых необходимо предусматривать отдельные контейнеры и места для размещения на площадках. Отмеченное, касается и отходов из пластика, для которых также необходима установка специальных сетчатых коробов, мест для их размещения [6] и использование специальной техники для их вывоза.

Предполагается, что на начальном этапе внедрения дуальной системы сортировки мусора будут применяться два цвета контейнеров: серый - для органических отходов («мокрого» мусора) и синий - для «сухого» мусора.

На сегодняшний день предложения на рынке контейнерного оборудования по цветовому решению и нанесению маркировки немногочисленны. Анализ данных сайта Регионального оператора свидетельствуют о том, что на рынке в основном представлены евроконтейнеры зеленого цвета без маркировки по видам отходов. А производителей полимерной тары, которые имеют среди ассортимента своей продукции контейнеры серого и синего цвета и, предлагающих бесплатное нанесение маркировки, немного: Ай-Пласт и РГ-Экотек.

\section{Материалы и методы исследования}

По мнению авторов, устойчивое эколого-экономическое развитие территории тесно связывается с принципом предикативности и процессами экологизации производства, следование которым обеспечит регламентацию деятельности и защищенность интересов хозяйствующих субъектов и населения, предупреждение неблагоприятных ситуаций в инвестиционной и производственной сферах.

Сфера сбора, транспортировки и утилизации отходов не является исключением и также должна строиться с учетом требований эколого-экономической безопасности [20, 23, 26-27, 29-30], особенно в условиях ее реформирования. Выделяя в механизме управления эколого-экономической безопасностью региона его ключевые элементы (подсистемы, обеспечивающие адаптивность механизмов к внешним воздействиям), представленные на рисунке, авторы форму- 
лируют критерии эколого-экономической безопасности (ЭЭБ), закладываемые в систему оценки проводимых «мусорной» реформой мер. Авторы считают, что обеспечить реализацию принципа предикативности можно лишь во взаимодействии трех подсистем безопасности, в этой связи и критерии ЭЭБ строятся исходя из свойств, определяющих устойчивость данных подсистем (рис.):

- техника и технология;

- законодательство и нормативно-правовые акты;

- финансовые (инвестиционные) ресурсы.

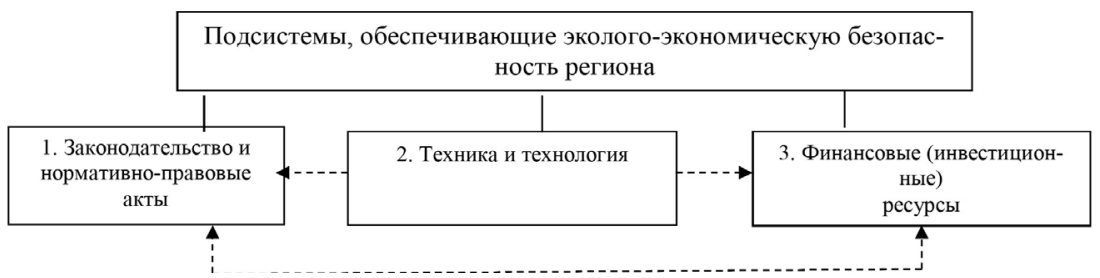

Рис. Взаимосвязь подсистем, обеспечивающих эколого-экономическую безопасность региона

1. Подсистема «Законодательство и нормативно правовые акты».

Значимость данной подсистемы заключается в том, что адекватное экологическое законодательство является одним из инструментов государственного регулирования и главным условием эффективного решения проблемы обеспечения экологической безопасности.

Действующая система российского экологического законодательства не может быть признана целостной и сбалансированной в виду существующей несогласованности между экологическим, хозяйственным и иным законодательством. Экологические требования не всегда учитываются при формировании нормативно-правовых актов иных отраслей законодательства. В свою очередь, Федеральное экологическое законодательство не в полной мере учитывает специфику региональных проблем, в связи с чем, их решение требует специального закрепления в законодательстве на уровне субъектов Федерации или принятия иных нормативно-правовых актов.

В связи с отмеченным, вводится первый критерий ЭЭБ для оценки адекватности мер, принимаемых в ходе реформы: для обеспечения 
соответствия экологическим нормативам экологические требования должны учитываться при формировании нормативно-правовых актов хозяйственного и иных отраслей законодательства.

2. Подсистема «Техника и технология» включает следующие направления:

- расширение применения разработанных инженерно-технических решений по очистке от вредных веществ выбросов и сбросов;

- разработка принципиально новых и совершенствование действующих методов и технологий по очистке выбросов и сбросов от загрязняющих веществ;

- создание и внедрение прогрессивных малоотходных технологий;

- развитие производств по выпуску экологически чистых продуктов;

- расширение номенклатуры, увеличение объемов и повышение эффективности использования техногенных образований;

- организация безотходных производств, предусматривающих постадийную переработку образующихся в технологической цепочке отходов.

Подчеркивая особую роль подсистемы «Техника и технология» в связи с крайней изношенностью производственно-технической основы у большинства предприятий Свердловской области, формулируем второй критерий ЭЭБ: технико-технологическое обеспечение должно строчться с учетом принципа соответствия наилучшим доступным технологиям.

3. Подсистема «Финансовые (инвестиционные) ресурсы».

Решение проблем эколого-экономической безопасности требует значительного финансового обеспечения. Основным источником такого финансирования выступают экологические платежи предприятий за использование природных ресурсов и за загрязнение окружающей природной среды, которые в силу своей незначительности не выполняют возложенной на них функции. Поэтому, в условиях действующей системы платежей, важно исследовать и другие варианты финансового обеспечения, например, формы инвестирования компаний (предприятий) при которых финансовые ресурсы транс- 
формируются в ресурсы инвестиционные на основе реализации экологических проектов. Исходя из отмеченного, вводится третий критерий ЭЭБ для оценки адекватности мер, принимаемых в ходе реформы: использование финансовых инструментов, обеспечивающзих эффективность функционирования системь .

В процессе реализации «мусорной» реформы возникает множество не только организационных, техническо-технологических проблем, связанных с разделением, транспортировкой, утилизацией ТКО, но и с понятиями: «отходы», коммунальные отходы и т.д.

С целью уточнения терминов «мусор», ТКО, градации отходов и ТКО необходимо обратиться к Межгосударственному стандарту ГОСТ 30772-2001 «Ресурсосбережение. Обращение с отходами. Термины и определения» [10]. В нем приводится расширенное определение отходов потребления, которое авторы принимают как базовое: «под отходами потребления, следует считать остатки веществ, материалов, предметов, изделий, товаров (продукции или изделий), частично или полностью утративших свои первоначальные потребительские свойства для использования по прямому или косвенному назначению в результате физического или морального износа в процессах общественного или личного потребления (жизнедеятельности), использования или эксплуатации».

В ходе исследования использованы методы анализа научной и нормативно-правовой литературы, методы теоретических и эмпирических исследований, экономический и финансовый анализ, данные статистики.

\section{Результаты исследования и их обсуждение}

Правовое обеспечение «мусорной» реформы (экологические требования должны учитываться при формировании нормативноправовых актов хозяйственного и иных отраслей законодательства).

Твердые коммунальные отходы определяются, как мусор, формирующийся и накапливающийся в жилых помещениях в ходе деятельности человека, а также потребительские товары, потерявшие свои 
полезные свойства. К коммунальным отходам законодатели относят отходы юридических лиц и индивидуальных предпринимателей, схожие по компонентному составу с обычным бытовым мусором.

Под сбором отходов в законодательстве понимается прием отходов в целях их дальнейшей обработки, утилизации, обезвреживания, размещения лицом, осуществляющим их обработку, утилизацию, обезвреживание, размещение [15, ст. 1]. Сбор ТКО происходит с помощью специального оборудования - контейнеров для мусора, а также приемных бункеров для крупногабаритных отходов. Нормативные определения понятий контейнер, бункер содержатся в Постановлении Правительства РФ от 12.11.2016 №1156 (ред. от 15.12.2018) «Об обращении с твердыми коммунальными отходами и внесении изменения в постановление Правительства Российской Федерации от 25 августа 2008 г. №641» [14, п. 2]. Согласно Федеральному закону от 24.06.1998 №89-Ф3 (ред. от 07.04.2020) «Об отходах производства и потребления», сбор и накопление отходов может производиться только в специально оборудованных для этого местах - контейнерных площадках, обустроенных в соответствии с законодательством РФ, санитарным требованиями [17, п. 1.7], а также правилами благоустройства муниципальных образований.

Данные вопросы регулируются законодательством субъектов РФ и региональными нормативно-правовыми актами Свердловской области. Так, например, постановление Правительства Свердловской области от 26 декабря 2018 года №969-ПП «Об утверждении Порядка накопления твердых коммунальных отходов (в том числе их раздельного накопления) на территории Свердловской области (с изменениями на 23 января 2020 года)» [16] включает новое для жителей региона понятие - дуальная система раздельного накопления ТКО.

Ввод системы раздельного накопления ТКО, при которой непищевые компоненты ТКО, не загрязненные, пригодные к утилизации, размещаются в одном контейнере, а морфологические компоненты ТКО, не подлежащие утилизации, а также загрязненные и органические (пищевые) отходы размещаются в другом контейнере [16, п. 3], планировался с июля 2020 года. При этом для замыкания процесса 
использования органического мусора, предлагается производить из него биогрунт, который будет использоваться для рекультивации существующих свалок. Однако за последующий период не появилось ни дополнительных опций в системах расчетов тарифов за перевозки, платежей ЖКХ, ни разъяснений по компенсационным схемам для переработчиков мусора.

Важно и другое - введение системы дуального сбора мусора вызвало проблему, связанную с реформированием системы транспортирования отходов.

Согласно Федеральному закону «Об отходах производства и потребления», транспортирование отходов - это перемещение отходов с помощью транспортных средств вне границ земельного участка, находящегося в собственности юридического лица или индивидуального предпринимателя, либо предоставленного им на иных правах [15, ст. 1]. Также это деятельность, связанная с перемещением отходов между местами или объектами их образования, накопления, хранения, захоронения и размещения. К такому виду работ как «транспортирование отходов» с позиций экологической безопасности предъявляются определенные требования. Предприятие при осуществлении такой деятельности должно исключить возможность потерь отходов по пути следования и аварийные ситуации. Кроме того, транспортирование отходов должно осуществляться при соблюдении ряда условий, установленных Федеральным законом «Об отходах производства и потребления» [15, ст. 16]. Обязательным является и наличие паспорта отходов, который представляет собой документ, в содержании которого отражена информация о мусоре и юридическом лице, ответственном за его возникновение, использование, размещение и ликвидацию.

Наличие специально оборудованных и снабженных специальными знаками транспортных средств - еще одно требование для выполнения организациям, оказывающим услуги по транспортировке отходов. При этом неотъемлемым является соблюдение требований безопасности к транспортированию отходов на транспортных средствах, наличие документации для транспортирования и передачи 
отходов с указанием количества транспортируемых отходов, цели и места назначения их транспортирования [24]. Подобным документом, по мнению специалистов, может быть путевой лист, который будет выдаваться водителю перед каждым совершаемым им рейсом.

Для транспортирования отходов производства и потребления также должен использоваться специальный транспорт-мусоровоз. Оператор по обращению с твердыми коммунальными отходами, осуществляющий деятельность по транспортированию твердых коммунальных отходов, обязан владеть мусоровозами, отвечающими общим техническим требованиям и требованиям безопасности, установленным законодательством РФ о техническом регулировании (Постановление Правительства РФ от 12 ноября 2016 № 1156 (ред. от 15.12.2018) «Об обращении с твердыми коммунальными отходами...» [14, п. 2].

\section{Технико-технологическое обеспечение «мусорной реформы»} (технико-технологическое обеспечение должно строиться с учетом принципа соответствия наилучиим доступным технологиям).

Мусоровозная техника должна быть оснащена средствами спутниковой навигации - на ней должно быть установлено специальное бортовое устройство, позволяющее отслеживать местоположение автомобиля в реальном времени, а также его маршрут [8, с. 37]. Кроме того, в отношении каждого мусоровоза должен вестись маршрутный журнал по форме, утвержденной уполномоченным органом исполнительной власти субъекта Российской Федерации, в котором указывается информация о движении мусоровоза и загрузке (выгрузке) твердых коммунальных отходов.

В настоящее время в Свердловской области ООО «ТрансСервис», которое является генеральным подрядчиком регионального оператора, осуществляет подготовку к реформированию системы транспортирования отходов.

На сегодняшний день на рынке у поставщиков специальной техники в основном имеются варианты мусоровозов для селективного сбора и перевозки мусора с двумя и более раздельных бункера на одном шасси. Такие транспортные средства представлены в ассор- 
тименте АО «Коминвест-АКМТ» - официального дистрибьютера итальянской марки Farid, а также АО «Автобау» - представитель турецкой марки HIDRO-MAK. Отечественная техника для раздельной транспортировки отходов пока отсутствует на рынке.

Помимо проблемы обеспечения специальной техникой важнейшей частью «мусорной» реформы, определяющей эффективность ее проведения, является оценка наличия объектов размещения отходов и мусороперерабатывающих заводов, служащая для определения возможности увеличения пропускной способности. По данным Свердловского областного кадастра отходов производства и потребления на территории Административно-производственного округа (АПО) №3 находится 221 объект размещения отходов - полигоны ТКО, представляющие собой как открытые площадки, так и закрытые бункеры, из них 38 объектов размещения твердых коммунальных отходов, включены в Государственный реестр объектов размещения отходов [22]. Также на территории АПО №3 расположены действующие объекты переработки ТКО общей мощностью чуть меньше 200 тыс. т/год. В долгосрочных планах на территории области к 2026 году намечается передавать на утилизацию, обезвреживание и переработку до 60\% отходов, построив для этого 12 новых мусоросортировочных комплексов [22].

Анализ обозначенных выше проблем позволяет сделать следующий вывод: «мусорная» реформа создала предпосылки для формирования нового сектора экономики, объединяющего как сферу ЖКХ (подготовка), так и производство спецтехники и переработки отходов, оказание транспортных услуг.

Финансовые инструменты и формы инвестирования приобретения транспортных средств в условиях «мусорной» реформы (использование финансовых инструментов, обеспечивающих эффективность функиионирования системь)

Введение дуальной сортировки мусора, являющейся продолжением «мусорной» реформы, породило немаловажную проблему, требующую своего решения: рост финансовых рисков хозяйствую- 
щих субъектов из-за реформирования системы транспортирования отходов, включая приобретение спецтехники.

Как свидетельствуют источники [18] в 2019 году продажи мусоровозов в России увеличились практически в два раза. За 9 месяцев 2019 года объем рынка новых машин составил 2,6 тыс. единиц, что на 93\% больше, чем за тот же предыдущий период. Становится очевидным, что в условиях реформы выбор поставщика для организации-подрядчика является основным моментом в установлении форм инвестирования и источников финансирования, поскольку существенно снижает ее финансовые риски.

В соответствие с требованиями к транспорту по вывозу ТКО из всех организаций-поставщиков наиболее предпочтительной для Свердловской области является компания АО «Коминвест-АКМТ» [2]. Она предлагает разнообразную технику для транспортирования отходов: мусоровозы с задним и боковым типом загрузки, автомобили для сбора и вывоза отходов из заглубленных контейнеров, машины для мойки контейнеров, а также эксклюзивные машины для селективного сбора мусора с двумя независимыми бункерами на одном шасси. Кроме того, АО «Коминвест-АКМТ» предоставляет возможность использования различных схем лизинга для организаций и индивидуальных предпринимателей всех регионов Российской Федерации и стран СНГ. Стоимость предмета лизинга составляет от 150000 рублей, при этом авансовый платеж от 0\% (в зависимости от программы, типа оборудования, условий производства и поставки, сроков договора). Среди партнеров АО «КоминвестАКМТ» такие компании как АО «Сбербанк Лизинг», ООО «УралБизнесЛизинг» и др.

Важным звеном работы по снижению финансовых рисков является выбор источника финансирования. Известно, что помимо непосредственной покупки оборудования за счет собственных средств, существуют и другие финансовые инструменты, наиболее популярными из них в настоящее время выступают банковские кредиты и лизинг.

И хотя, по-прежнему, наиболее простым способом приобретения оборудования для производственных нужд организации, является 
покупка за счет собственных средств, которая позволяет оперативно решать вопросы, связанные с приобретением (модернизацией) основных средств, не тратиться на оплату расходов, сопровождающих использование кредитов (займов), она имеет свои минусы. Данный источник финансирования является наиболее приемлемым, однако его недостатки также очевидны: у предприятия должна быть достаточная сумма денежных средств на расчетном счете для исполнения оплаты поставщику, возникают транзакционные издержки, связанные с самостоятельностью поиска и подбором необходимой техники, выбором поставщика, организацией поставки, заключения договора купли-продажи и др.

Внешними источниками финансирования для приобретения основных средств для организации-подрядчика являются кредитование юридических лиц и лизинг. По данным Центрального Банка России на 1 января 2019 года объем кредитных средств, предоставленных коммерческими банками юридическим лицам и индивидуальным предпринимателям, равнялся 40 триллионам рублей [19]. Среди положительных сторон кредита можно выделить такие как: широкий выбор условий кредитования, которые возникают вследствие конкуренции между банками, возможность получения крупной суммы на развитие бизнеса, обновление основных фондов, наличие программ поддержки малого и среднего предпринимательства. Однако минусы этой формы финансирования также хорошо известны: возникновение затруднений, связанных с подготовкой пакета необходимых документов и заполнением специфических форм отчетности для банковского мониторинга, отказ в кредитовании.

Другой, наиболее распространенной формой использования заемных средств является лизинг [25]. Отдельно стоит отметить преимущество лизинга для организаций, оказывающих транспортные услуги (в том числе услуги вывоза отходов), которое заключается в возможности начать эксплуатацию автомобилей при минимальных начальных капиталовложениях. По истечении срока лизинга автомобиль может перейти в собственность покупателя (последнее зависит от условий заключаемого договора). Следовательно, лизинг 
автомобилей может способствовать высвобождению значительной части финансовых активов, необходимых для развития предприятия. Данный вывод подтверждается и результатами расчетов, выполненных для ООО «ТрансСервис»: покупка 5 единиц техники при разных источниках финансирования (таблица).

Таблица.

Сравнение вариантов приобретения основных средств, тыс. руб. ${ }^{1}$

\begin{tabular}{|l|c|c|c|c|c|c|}
\hline \multirow{2}{*}{\multicolumn{1}{|c|}{ Показатель }} & \multicolumn{2}{c|}{$\begin{array}{c}\text { Покупка } \\
\text { (собственные) }\end{array}$} & \multicolumn{2}{c|}{ Кредит } & \multicolumn{2}{c|}{ Лизинг } \\
\cline { 2 - 8 } & 1 -й год & 3а 3 года & 1 -й год & 3а 3 года & 1 -й год & 3а 3 года \\
\hline Аванс & - & - & 2500,00 & 2500,00 & 6129,66 & 6129,66 \\
\hline $\begin{array}{l}\text { Основные платежи, в } \\
\text { т.ч. НДС }\end{array}$ & 52500,00 & 52500,00 & $19643,23 *$ & $58929,69 *$ & 25102,25 & 60663,78 \\
\hline НДС к возмещению & 8750,00 & 8750,00 & $8750,00 * *$ & $8750,00 * *$ & 4183,70 & 10110,63 \\
\hline $\begin{array}{l}\text { Дополнительные рас- } \\
\text { ходы, }\end{array}$ & 144,30 & 264,30 & 144,30 & 264,30 & 144,30 & 264,30 \\
\hline $\begin{array}{l}\text { Сумма начисленной } \\
\text { амортизации }\end{array}$ & 6177,50 & 18532,50 & 6177,50 & 18532,50 & 23600,32 & 45044,45 \\
\hline $\begin{array}{l}\text { Расходы, уменьшаю- } \\
\text { щие налоговую базу } \\
\text { по налогу на прибыль }\end{array}$ & 6321,80 & 18965,40 & 11086,50 & 27895,09 & 21062,84 & 50986,05 \\
\hline $\begin{array}{l}\text { Экономия по налогу } \\
\text { на прибыль }\end{array}$ & 1264,36 & 3793,08 & 2217,30 & 5539,02 & 4212,56 & 10197,20 \\
\hline Общая сумма затрат & 42629,94 & 40389,82 & 11320,22 & 47533,57 & 22979,93 & 46981,50 \\
\hline
\end{tabular}

*Платеж по кредиту не содержит НДС.

**НДС возмещен со стоимости имущества.

Таким образом, в условиях проведения масштабной «мусорной» реформы, лизинг можно рассматривать как наиболее приемлемый и эффективный источник финансирования. Дополнительно отметим следующие его преимущества:

- отсутствие необходимости обеспечения лизинговой сделки залогом, тогда как при кредитовании необходима сумма не менее 50\% суммы кредита;

- возможность применения ускоренной амортизации, что позволяет уменьшить платежи по налогу на имущество после завершения сделки (однако это неприменимо к транспортным

\footnotetext{
${ }^{1}$ Составлено авторами по $[2,4,26]$.
} 
средствам, поскольку налоговой базой транспортного налога является мощность двигателя автомобиля) и уменьшить платежи по налогу на прибыль, за-за увеличения размера амортизационных отчислений предмета лизинга [3];

- отнесение на себестоимость всех лизинговых платежей (не относятся только выкупные платежи), в то время как при кредитовании на себестоимость относятся только проценты по кредиту в пределах, установленных статьей 269 Налогового Кодекса РФ [11];

- более короткие сроки рассмотрения заявок на лизинг, чем на кредит;

- требования, предъявляемые к лизингополучателю с точки зрения рентабельности и финансовой устойчивости менее жёсткие, чем требования к заёмщику при получении кредита (нормативы, установленные Центральным банком РФ и внутренние нормативы ликвидности, кредитоспособности банка [21]);

- гибкие условия расчета графика платежей и возможность изменения его в течение лизинга, что важно организациям с сезонным видом работ [9];

- прием НДС к зачету при уплате в бюджет, в то время как при кредитовании, к зачету принимается НДС, уплаченный от первоначальной стоимости имущества [1].

Таким образом, исследование возможных источников финансирования показало, что наиболее приемлемылм с точки зрения безопасности (основываясь на сравнении чистых затрат), является вариант лизинга. Его преимущества состоят в отсутствии необходимости обеспечения сделки залогом, возможности применения ускоренной амортизации, отнесении на себестоимость суммы лизинговых платежей, организации более гибких условий оплаты, составление графика с учетом индивидуальных особенностей получателя.

\section{Заключение}

В исследовании авторами выделены в механизме управления эколого-экономической безопасностью региона его ключевые под- 
системы и предложены критерии ЭЭБ, закладываемые в систему оценки реализуемых мер по проведению «мусорной» реформы, рассмотренные в разрезе блоков: 1) законодательства и нормативно-правовых актов; 2) техники и технологии; 3) финансовых (инвестиционных) ресурсов.

Полученные по результатам анализа выводы свидетельствуют о следующем:

1) с точки зрения обоснования для населения обязательств по сортировке мусора необходимо внести в нормативно-правовые акты хозяйственного законодательства вопросы, связанные с процедурой учета фактических данных сортируемого мусора и с регулированием тарифов в сфере перевозок и ЖКХ. Последнее позволит сделать систему начислений для перевозчиков и населения более гибкой, так как дает возможность перейти от расчетов «по нормативу» к фактическим данным по объему и, вероятно, скажется на снижении тарифов;

2) переход на принцип использования наилучшей из доступных технологий открывает большие возможности для организации производства отечественной техники, предназначенной для раздельной транспортировки отходов, которая в настоящее время представлена на рынке в единичных вариантах. Не соответствуют потребностям «мусорной» реформы мощности и объектов размещения отходов, и мусороперерабатывающих заводов. На сегодняшний день возможности по объему перерабатываемого мусора г. Екатеринбурга составляет менее 5 процентов, поэтому запрос на приобретение мусоросортировочных линий и на строительство заводов по переработке отходов, использующих новые технологические решения, будет возрастать;

$3)$ расширение источников финансирования «мусорной» реформы потребовало оценки эффективности применения отдельных финансовых инструментов, широко используемых в практике хозяйственной деятельности предприятий данной сферы. Исследование возможных источников финансирования показало, что наиболее эффективным и приемлемым с точки зрения безопасности (основываясь на сравнении чистых затрат), является вариант лизинга. 


\section{Сиисок литературы}

1. Адамов Н.А., Тилов А.А. Приобретение основных средств: взять в лизинг или купить, что выгоднее? // Управленческий учет. 2006. №10(178). C. 17-20. URL: https://cyberleninka.ru/article/n/priobretenie-osnovnyhsredstv-vzyat-v-lizing-ili-kupit-chto-vygodnee (дата обр. 26.04.2020).

2. АО «Коминвест-АКМТ. М., 2020. URL: http://www.cominvest-akmt. ru/ (дата обращения: 28.08.2020).

3. Афанасьева Н.Д. Лизинг: преимущества и недостатки // Молодой ученый. №4(294). 2020. С. 92-94. URL: https://moluch.ru/ archive/294/66777/ (дата обращения: 26.04.2020).

4. Борисова Л. Мусор пойдет в печь. Из ТКО начнут производить топливо. URL: https://rg.ru/2020/03/12/reg-urfo/na-urale-iz-bytovyh-othodovstanut-proizvodit-rdf-toplivo.html (дата обращения: 28.08.2020).

5. Васильев А.Н., Мордовченков Н.В. Раздельный сбор отходов при эксплуатации коммерческой недвижимости как механизм повышения экономической эффективности организаций сферы услуг // Отходы и ресурсы. 2019. Том 6. №2. С. 1.

6. Изнанка мусорного сервиса: на чем и как возит отходы «Спецавтобаза». URL: https://www.uralinform.ru/news/society/303088-iznanka-musornogoservisa-na-chem-i-kak-vozit-othody-specavtobaza/ (дата обр.: 20.08.2020).

7. Какие контейнеры и для какого мусора используются? URL: https:// torg-koms.ru/novosti/stati/kakie-konteynery-i-dlya-kakogo-musoraispolzuyutsy/ (дата обращения: 20.08.2020).

8. Киселёва Е.Б. Нюансы транспортирования отходов и особенности его лицензирования // Твердые бытовые отходы. 2019. №9. С. 36-40.

9. Лещенко М.И. Основы лизинга: учебное пособие. М.: Изд. центр ЕАОИ, 2015. 360 с.

10. Межгосударственный стандарт ГОСТ 30772-2001 «Ресурсосбережение. Обращение с отходами. Термины и определения». URL: http:// docs.cntd.ru/document/gost-30772-2001 (дата обращения: 28.08.2020).

11. Налоговый кодекс Российской Федерации (часть вторая) от 05.08.2000 №117-Ф3 (ред. от 24.04.2020). URL: http://www.consultant. ru/document/cons_doc_LAW_28165/(дата обращения: 31.08.2020).

12.Никуличев Ю.В. Управление отходами. Опыт Европейского союза. Аналит. обзор / РАН. ИНИОН. Центр науч.-информ. исслед. глоб. 
и регионал. пробл. Отд. проб. европ. безопасности. М., 2017. 55 с. (Сер.: Социальные и экономические проблемы глобализации).

13. О контрактной системе в сфере закупок товаров, работ, услуг для обеспечения государственных и муниципальных нужд. Федеральный закон от 05.04.2013 №44-Ф3 (последняя редакция). URL: http://www.consultant. ru/document/cons_doc_LAW_144624/ (дата обращения: 28.08.2020).

14. Об обращении с твердыми коммунальными отходами и внесении изменения в постановление Правительства Российской Федерации от 25 августа 2008 г. №641. Постановление Правительства РФ от 12.11.2016 №1156 (ред. от 15.12.2018). URL: http://docs.cntd.ru/ document/420382731 (дата обращения: 28.08.2020).

15. Об отходах производства и потребления. Федеральный закон от 24.06.1998 №89-Ф3 (последняя редакция). URL: http://www. consultant.ru/document/cons_doc_LAW_19109/_LAW_19109/ (дата обращения: 28.08.2020).

16. Об утверждении Порядка накопления твердых коммунальных отходов (в том числе их раздельного накопления) на территории Свердловской области. Постановление Правительства Свердловской области от 26 декабря 2018 года №969-ПП. URL: http://docs.cntd.ru/ document/550302262 (дата обращения: 28.08.2020).

17. Об утверждении санитарно-эпидемиологических правил и нормативов СанПиН 2.1.7.-19 «Санитарно-эпидемиологические требования к содержанию территорий городских и сельских поселений» (подготовлен Роспотребнадзором 24.05.2019). Постановление Главного государственного санитарного врача Российской Федерации. URL: https://www. garant.ru/products/ipo/prime/doc/56695139/ (дата обращения: 28.08.2020).

18. Обзор рынка мусоровозов // Информационно-аналитическое издание Technomagazine. M., 2007-2020. URL: https://t-magazine.ru/pages/ refuse_vehicle/ (дата обращения: 28.08.2020).

19. Объем кредитов, предоставленных юридическим лицам - резидентам и индивидуальным предпринимателям в рублях, по видам экономической деятельности и отдельным направлениям использования средств // Банк России. М., 2002-2020. URL: https://cbr.ru/statistics/ table/?tableId=302-01 (дата обращения: 28.08.2020). 
20.Пирогова О.Е., Емельянов А.Н. Экономическое обоснование создания системы утилизации отходов для предприятий сферы услуг // Международный научный журнал. 2019. №3. С. 28-33.

21. Сурина И.В., Геращенко А.А. Сравнительный анализ лизинга и кредита // Экономика и социум. 2016. №12(31). C. 25-29. URL:https:// www.iupr.ru/domains_data/files/zurnal_31/Surina\%20I.\%20V.,\%20 Gerashenko\%20A.A..pdf (дата обращения: 26.04.2020).

22. Территориальная схема обращения с отходами производства и потребления на территории Свердловской области. URL: https://energy. midural.ru/wp-content/uploads/2020/02/TSv3.pdf (дата обращения: 28.08.2020).

23. Титов А.Б., Денисов В.М. Автономные системы комплексного мониторинга полигонов ТБО // Неделя науки СПБПУ: материалы научной конференции с международным участием. Санкт-Петербургский политехнический университет Петра Великого. Издательство: ПОЛИТЕХ-ПРЕСС, 2020. С. 195-198.

24. Транспортирование отходов I-IV класса опасности // Протос Экспертиза. Промышленная и экономическая безопасность. М., 2003-2020. URL: https://library.fsetan.ru/doc/transportirovanie-othodov-i-iv-klassaopasnosti/ (дата обращения: 28.08.2020).

25. Чиркова М.Ю. Договор лизинга: опыт экономико-правового анализа // В мире научных открытий. 2011. №7-1(19). С. 387-409.

26. Эколого-экономическая и энергетическая безопасность субъектов экономической деятельности / [И.С. Белик, А.В. Калина и др.]; под ред. В.В. Криворотова. М.: ЮНИТИ-ДАНА, 2019. 276 с.

27. Belik, I.S., Pryakhin, D.A. Social and ecological component of the sustainable development of region // Economy of Region. 2013. №3, pp. 142-151. DOI: 10.17059/2013-3-12.

28. Gentil E., Damgaard A., Hauschild M., et al. Models for waste life cycle assessment: Review of technical assumptions // Waste Management. 2010. Vol. 30. Is. 12, pp. 2636-2648.

29. Kuklin, A.A., Kuklina L.N., Korobkov I.V. Environmental security in the context of the current threats and regional socio-economic situation // International Multidisciplinary Scientific GeoConference Surveying Geol- 
ogy and Mining Ecology Management, SGEM 2019. Albena, Bulgaria. Volume 19, Issue 5.3, pp. 259-266. DOI: 10.5593/sgem2019/5.3/S21.033 30. Manzhurov I.L., Berg D.B., Korobitsyn B.A., Antonov K.L. Potential environmental hazard index as a waste management optimization criterion // OPT-i 2014 - 1st International Conference on Engineering and Applied Sciences Optimization, Proceedings, pp. 953-961.

31. Mavropoulos A. Megacities Sustainable development and Waste Management in the 21th Century. World Congress. Hamburg: ISWA, 2010.

32. Senchagov V.K., Mityakov S.N. Evaluation of economic crises using short-term indexes and average indexes of economic security of Russia // Studies on Russian Economic Development. 2016. №27(2), pp. 148 158. DOI: 10.1134/S1075700716020131.

33. Wilson D.C., Velis C.A., Rodic L. Integrated sustainable waste management in developing countries // Proceedings of the Institution of Civil Engineers. Waste and Resource Management. 2013. Vol. 166. Is. 2, pp. 52-68.

\section{References}

1. Adamov N.A., Tilov A.A. Priobretenie osnovnykh sredstv: vzyat' v lizing ili kupit', chto vygodnee? [Acquisition of fixed assets: lease or buy, which is more profitable?]. Upravlencheskiy uchet [Management Accounting], 2006, no. 10(178), pp. 17-20. URL: https://cyberleninka. $\mathrm{ru} /$ article/n/priobretenie-osnovnyh-sredstv-vzyat-v-lizing-ili-kupit-chto-vygodnee (accessed 26.04.2020).

2. $A O$ «Kominvest-AKMT. M., 2020. URL: http://www.cominvest-akmt. ru/ (accessed: 28.08.2020).

3. Afanas'eva N.D. Lizing: preimushchestva i nedostatki [Leasing: advantages and disadvantages]. Molodoy uchenyy [Young scientist], no. 4(294), 2020, pp. 92-94. URL: https://moluch.ru/archive/294/66777/ (accessed: 26.04.2020).

4. Borisova L. Musor poydet v pech'. Iz TKO nachnut proizvodit' toplivo [Garbage will go to the oven. Fuel will be produced from MSW]. URL: https://rg.ru/2020/03/12/reg-urfo/na-urale-iz-bytovyh-othodov-stanutproizvodit-rdf-toplivo.html (accessed: 28.08.2020).

5. Vasil'ev A.N., Mordovchenkov N.V. Razdel'nyj sbor othodov pri jeks-pluatacii kommercheskoj nedvizhimosti kak mehanizm povyshenija jekono- 
micheskoj jeffektivnosti organizacij sfery uslug [Separate waste collection during the operation of commercial real estate as a mechanism for increasing the economic efficiency of organizations in the service sector]. Othody i resursy [Waste and resources], 2019, V. 6, no. 2, pp. 1.

6. Iznanka musornogo servisa: na chem i kak vozit otkhody "Spetsavto$b a-z a »$ [The wrong side of the garbage service: what and how does Spetsavtobaza transport waste.]. URL: https://www.uralinform.ru/news/ society/303088-iznanka-musornogo-servisa-na-chem-i-kak-vozit-othody-specavtobaza/ (accessed: 20.08.2020).

7. Kakie konteynery i dlya kakogo musora ispol'zuyutsya? [What containers and for what waste are used?]. URL: https://torg-koms.ru/novosti/stati/kakie-konteynery-i-dlya-kakogo-musora-ispolzuyutsy/ (accessed: 20.08.2020).

8. Kiseleva E.B. Nyuansy transportirovaniya otkhodov i osobennosti ego litsenzirovaniya [Nuances of waste transportation and features of its licensing]. Tverdye bytovye otkhody [Solid domestic waste], 2019, no. 9, pp. 36-40.

9. Leshchenko M.I. Osnovy lizinga: uchebnoe posobie [Basics of leasing: a tutorial]. M.: Izd. tsentr EAOI, 2015. 360 p.

10. Mezhgosudarstvennyy standart GOST 30772-2001 «Resursosberezhe-nie. Obrashchenie s otkhodami. Terminy i opredeleniya» [Interstate standard GOST 30772-2001 «Resource saving. Waste management. Terms and Definitions»]. URL: http://docs.cntd.ru/document/gost-307722001 (accessed: 28.08.2020).

11. Nalogovyy kodeks Rossiyskoy Federatsii (chast'vtoraya)" ot 05.08.2000 N 117-FZ (red. ot 24.04.2020) [Tax Code of the Russian Federation (part two) dated 05.08.2000 №117-FZ (as amended on 24.04.2020).]. URL: http://www. consultant.ru/document/cons doc_LAW_28165/(accessed: 31.08.2020).

12. Nikulichev Ju.V. Upravlenie othodami. Opyt Evropejskogo sojuza. Analit. obzor [Waste management. The experience of the European Union. Analytical review]. RAN. INION. Centr nauch.-inform. issled. glob. i regional. probl. Otd. prob. evrop. bezopasnosti. M., 2017. 55 p.

13. O kontraktnoy sisteme $v$ sfere zakupok tovarov, rabot, uslug dlya obespecheniya gosudarstvennykh i munitsipal'nykh nuzhd. Federal'nyy zakon ot 05.04.2013 №44-FZ (poslednyaya redaktsiya) [About the contract system in the field of procurement of goods, works, services to 
meet state and municipal needs. Federal Law dated 05.04.2013 No. 44FZ (last edition)]. URL: http://www.consultant.ru/document/cons_doc_ LAW_144624/ (accessed: 28.08.2020).

14. Ob obrashchenii s tverdymi kommunal'nymi otkhodami $i$ vnesenii iz-meneniya v postanovlenie Pravitel 'stva Rossiyskoy Federatsii ot 25 avgusta 2008 g. №641. Postanovlenie Pravitel’stva RF ot 12.11.2016 №1156 (red. ot 15.12.2018) [On the handling of solid municipal waste and amending the Decree of the Government of the Russian Federation dated August 25, 2008 No. 641. Resolution of the Government of the Russian Federation of 12.11.2016 No. 1156 (as amended on 15.12.2018)]. URL: http:// docs.cntd.ru/document/420382731 (accessed: 28.08.2020).

15. Ob otkhodakh proizvodstva i potrebleniya. Federal'nyy zakon ot 24.06.1998 №89-FZ (poslednyaya redaktsiya) [About production and consumption waste. Federal Law of June 24, 1998 No. 89-FZ (last edition)]. URL: http://www.consultant.ru/document/cons_doc_ LAW_19109/_LAW_19109/(accessed: 28.08.2020).

16. Ob utverzhdenii Poryadka nakopleniya tverdykh kommunal'nykh otkhodov (v tom chisle ikh razdel'nogo nakopleniya) na territorii Sverdlovskoy oblasti. Postanovlenie Pravitel'stva Sverdlovskoy oblasti ot 26 dekabrya 2018 goda №969-PP [On approval of the Procedure for the accumulation of solid municipal waste (including their separate accumulation) in the territory of the Sverdlovsk region. Resolution of the Government of the Sverdlovsk Region dated December 26, 2018 No. 969-PP]. URL: http://docs.cntd.ru/document/550302262 (accessed: 28.08.2020).

17. Ob utverzhdenii sanitarno-epidemiologicheskikh pravil $i$ normativov SanPiN 2.1.7.-19 «Sanitarno-epidemiologicheskie trebovaniya k soderzhaniyu territoriy gorodskikh i sel'skikh poseleniy» (podgotovlen Rospotrebnadzorom 24.05.2019). Postanovlenie Glavnogo gosudarstvennogo sanitarnogo vracha Rossiyskoy Federatsii [On the approval of the sanitary and epidemiological rules and standards SanPiN 2.1.7.-19 "Sanitary and epidemiological requirements for the maintenance of the territories of urban and rural settlements" (prepared by Rospotrebnadzor on May 24, 2019). Resolution of the Chief State Sanitary Doctor of the Russian Federation]. URL: https://www.garant.ru/products/ipo/prime/ doc/56695139/ (accessed: 28.08.2020). 
18. Obzor rynka musorovozov [Review of the garbage truck market]. Technomagazine [Technomagazine]. M., 2007-2020. URL: https://t-magazine.ru/pages/refuse_vehicle/ (accessed: 28.08.2020).

19. Obem kreditov, predostavlennykh yuridicheskim litsam - rezidentam i individual'nym predprinimatelyam v rublyakh, po vidam ekonomicheskoy deyatel'nosti i otdel'nym napravleniyam ispol'zovaniya sredstv [The volume of loans granted to legal entities - residents and individual entrepreneurs in rubles, by type of economic activity and certain areas of use of funds]. Bank Rossii. M., 2002-2020. URL: https://cbr.ru/statistics/table/?tableId=302-01 (accessed: 28.08.2020).

20.Pirogova O.E., Emel'janov A.N. Jekonomicheskoe obosnovanie sozda-nija sistemy utilizacii othodov dlja predprijatij sfery uslug [Economic substantiation of the creation of a waste disposal system for service enterprises]. Mezhdunarodnyj nauchnyj zhurnal [International scientific journal], 2019, no. 3, pp. 28-33.

21. Surina I.V., Gerashchenko A.A. Sravnitel'nyy analiz lizinga i kredita [Comparative analysis of leasing and credit]. Ekonomika $i$ sotsium [Economy and society], 2016, no. 12(31), pp. 25-29. URL: https:/www.iupr.ru/ domains_data/files/zurnal_31/Surina\%20I.\%20V.,\%20Gerashenko\%20 A.A.pdf (accessed: 26.04.2020).

22. Territorial'naya skhema obrashcheniya s otkhodami proizvodstva $i$ potrebleniya na territorii Sverdlovskoy oblasti [Territorial scheme of production and consumption waste management on the territory of the Sverdlovsk region.]. URL: https://energy.midural.ru/wp-content/uploads/2020/02/TSv3.pdf (accessed: 28.08.2020).

23. Titov A.B., Denisov V.M. Avtonomnye sistemy kompleksnogo monitoringa poligonov TBO [Autonomous systems for integrated monitoring of solid waste landfills]. Nedelja nauki SPBPU: materialy nauchnoj konferencii s mezhdunarodnym uchastiem. Sankt-Peterburgskij politehnicheskij universitet Petra Velikogo [SPBPU Science Week: proceedings of a scientific conference with international participation. Peter the Great St. Petersburg Polytechnic University]. Izdatel'stvo: POLITEH-PRESS, 2020, pp. 195-198.

24. Transportirovanie otkhodov I-IV klassa opasnosti [Transportation of waste of I-IV hazard class]. Protos Ekspertiza. Promyshlennaya i eko- 
nomicheskaya bezopasnost' [Protos Expertise. Industrial and economic security]. M., 2003-2020. URL: https://ibrary.fsetan.ru/doc/transportirovanie-othodov-i-iv-klassa-opasnosti/ (accessed: 28.08.2020).

25. Chirkova M.Ju. Dogovor lizinga: opyt jekonomiko-pravovogo analiza [Leasing agreement: experience of economic and legal analysis]. $V$ mire nauchnyh otkrytij [In the world of scientific discoveries], 2011, no. 7-1(19), pp. 387-409.

26.Ekologo-ekonomicheskaya i energeticheskaya bezopasnost'sub"ektov ekonomicheskoy deyatel'nosti [Ecological, economic and energy security of subjects of economic activity] / [I.S. Belik, A.V. Kalina i dr.]; pod red. V.V. Krivorotova. M.: YuNITI-DANA, 2019. 276 p.

27. Belik, I.S., Pryakhin, D.A. Social and ecological component of the sustainable development of region. Economy of Region, 2013, no. 3, pp. 142-151. DOI: 10.17059/2013-3-12.

28. Gentil E., Damgaard A., Hauschild M., et al. Models for waste life cycle assessment: Review of technical assumptions. Waste Management, 2010, vol. 30, is. 12, pp. 2636-2648.

29. Kuklin, A.A., Kuklina L.N., Korobkov I.V. Environmental security in the context of the current threats and regional socio-economic situation. International Multidisciplinary Scientific GeoConference Surveying Geology and Mining Ecology Management, SGEM 2019. Albena, Bulgaria, vol. 19, issue 5.3, pp. 259-266. DOI: 10.5593/sgem2019/5.3/S21.033.

30. Manzhurov I.L., Berg D.B., Korobitsyn B.A., Antonov K.L. Potential environmental hazard index as a waste management optimization criterion. OPT-i 2014 - 1st International Conference on Engineering and Applied Sciences Optimization, Proceedings, pp. 953-961.

31. Mavropoulos A. Megacities Sustainable development and Waste Management in the 21th Century. World Congress. Hamburg: ISWA, 2010.

32. Senchagov V.K., Mityakov S.N. Evaluation of economic crises using short-term indexes and average indexes of economic security of Russia. Studies on Russian Economic Development, 2016, no. 27(2), pp. 148-158. DOI: 10.1134/S1075700716020131.

33. Wilson D.C., Velis C.A., Rodic L. Integrated sustainable waste management in developing countries. Proceedings of the Institution of Civ- 
il Engineers. Waste and Resource Management, 2013, vol. 166, is. 2, pp. 52-68.

\section{ДАННЫЕ ОБ АВТОРАХ}

Белик Ирина Степановна, доктор экономических наук, профессор кафедры «Экономическая безопасность производственных комплексов»,

Уральский федеральный университет имени первого Президента России Б.Н. Ельцинна

ул. Мира, 19, г. Екатеринбург, 620002, Российская Федераџия irinabelik2010@mail.ru

Никулина Наталья Леонидовна, кандидат экономических наук, доцент кафедры шахматного искусства и компьютерной математики

Уральский государственный экономический университет ул. 8 Марта/Народной Воли, 62/45, г. Екатеринбург, 620144, Российская Федерация nikulina_nl@usue.ru

Аликберова Тамила Тагировна, аспирант кафедры «Экономическая безопасность производственных комплексов» Уральский федеральный университет имени первого Президента России Б.Н. Ельичина ул. Мира, 19, г. Екатеринбург, 620002, Российская Федерациия tamila.alikberova@mail.ru

Люцева Алена Евгеньевна, студент кафедры «Экономическая безопасность производственных комплексов» Уральский федеральный университет имени первого Президента России Б.Н. Ельцина

ул. Мира, 19, г. Екатеринбург, 620002, Российская Федераџия alen.liutseva@yandex.ru 


\section{DATA ABOUT THE AUTHORS}

Belik Irina Stepanovna, Doctor of Economics, Professor of the Department of Economic Security of Industrial Complexes

Ural Federal University named after the first President of Russia B.N. Yeltsin

19, Mira str., Yekaterinburg, 620002, Russian Federation irinabelik2010@mail.ru

SPIN-code: 4611-4490

Scopus Author ID: 55960087600

Nikulina Natalia Leonidovna, $\mathrm{PhD}$ in Economics, Associate Professor of the Department of Chess Art and Computer Mathematics Ural State University of Economics

8 March / Narodnaya Volya str., 62/45, Yekaterinburg, 620144, Russian Federation

nikulina_nl@usue.ru

SPIN-code: 1677-4125

ORCID: 0000-0002-6882-3172

ResearcherID: J-9846-2013

Scopus Author ID: 55960144700

Alikberova Tamila Tagirovna, post-graduate student of the Department of Economic Security of Industrial Complexes

Ural Federal University named after the first President of Russia B.N. Yeltsin

19, Mira str., Yekaterinburg, 620002, Russian Federation tamila.alikberova@mail.ru

Lyutseva Alena Evgenievna, student of the Department of Economic Security of Industrial Complexes

Ural Federal University named after the first President of Russia B.N. Yeltsin

19, Mira str., Yekaterinburg, 620002, Russian Federation alen.liutseva@yandex.ru 